\title{
Research on the Modern Industrial Product Art Design New Pattern from the Perspective of Color Design and Beautification
}

\author{
Beili Liu ${ }^{1}$ \\ ${ }^{1}$ Hankou University, \\ Wuhan, Hubei , 430000 China
}

\begin{abstract}
In this paper, we conduct research on modern industrial product art design new pattern from the perspective of color design and beautification. Product color if handled well could coordinate model or make up for the insufficient, make the product more easily won the favor of consumers, receive the twice the result with half the effort. When almost the same function in the use of industrial products, art design style of the product conforms to the public's aesthetic psychology, this product can be popular, such as streamline design is popular among people. Our research help enhance the current design pattern which will be necessary and important.
\end{abstract}

Keywords: Industrial Product; Art Design; Color Design; Beautification Perspective.

\section{Introduction}

Aesthetic function and artistic quality of the products is one of the purposes of industrial design. When the design has solved the material technology products technical subject and use function, art became his never-ending pursuit. In the case of manufacturing level and international commodity competition, mainly design competition. When almost the same function in the use of industrial products, art design style of the product conforms to the public's aesthetic psychology, this product can be popular, such as streamline design is popular among people. By people in the form of this design on the psychological acceptance, in order to achieve the designer in the economic and moral, the influence of the mass aesthetic aspects, strengthen the social identity of the product design. Therefore, the basic concept of industrial design in industrial design theory and practice plays a very important and active role. Form is the basis of the research model art design, is a scientific method, and the creation of the understanding of the in the field of design and art and organization, structure, construction, meaning such as composition, shape, including plane composition, color composition, three-dimensional construction. Form is the basis of product modeling design, compared with the representational form, it is more extensive. Before is used in actual design, must learn to use the visual language of art, for the creation of the visual aspects, understand modelling idea, training of skilled skill and performance method, training and cultivation of aesthetics and beauty feeling, improve the ability of creative activities and modelling from the perspective of art product modeling design [1].

In the law of human visual perception of the human eye to color faster than the perception of shape, for distant objects, we may can't see it form, but must be able to perceive its color. Many companies are also gradually realized the significance of color to the product in the product to keep up with the pace of modern life color design and color of popular trend, constantly on the style, make all kinds of products slowly into the era of artistic fashion appearance. Planar formation is the visual elements in the two dimensional plane, according to the visual effect of beauty, the principle of mechanics, arrangement and combination, to create the 
image and it is rational and logical reasoning research between the image and the image array method. For effective application in product design examples could be summarized as the follows. (1) Launch. Launch is a special kind of repetition and shape is arranged around the center of one or several common, like the sun light in natural life, blooming flowers, splash and so on. Launch has strong sense of focus and light, rich rhythm and rhythm. The launch of the constitution principle, product design often applied to the modelling of lamps and lanterns design. (2) Repeat. It refers to the same modelling of repeated formations. In product design, the repetitive structure of application is very extensive, such as cell phone button, and the product key, the arrangement of product modeling of repeat, also has a pattern of repeated arrangement, etc., can repeat a coordinated look and feel, and easy to remember, if the application is also easy to memory in the arrangement of some buttons, convenient operation, but if the application is not reasonable, also easy to produce the result that monotonous, so when you arranged to pay attention to the direction and space between them. (3) Special. Specific refers to regular breakthrough and individual elements appear prominent and conspicuous. Specific inclusions in regularity and specific part number should not be too much, should choose comparatively prominent position on the screen form the visual focus. Break the monotonous pattern, make the person surprise. Also is a kind of contrast, by using the method of specific contrast to change people's psychological activity, can stimulate the visual, so often used in product design. (4) Segmentation. In composition, the whole into parts, called segmentation, is everywhere in life. For example the condole top of the building, newspaper and magazine pages, the space in the refrigerator, is based on the principle of division. So split application in modern product design is very common [2]. The figure one shows the examples.
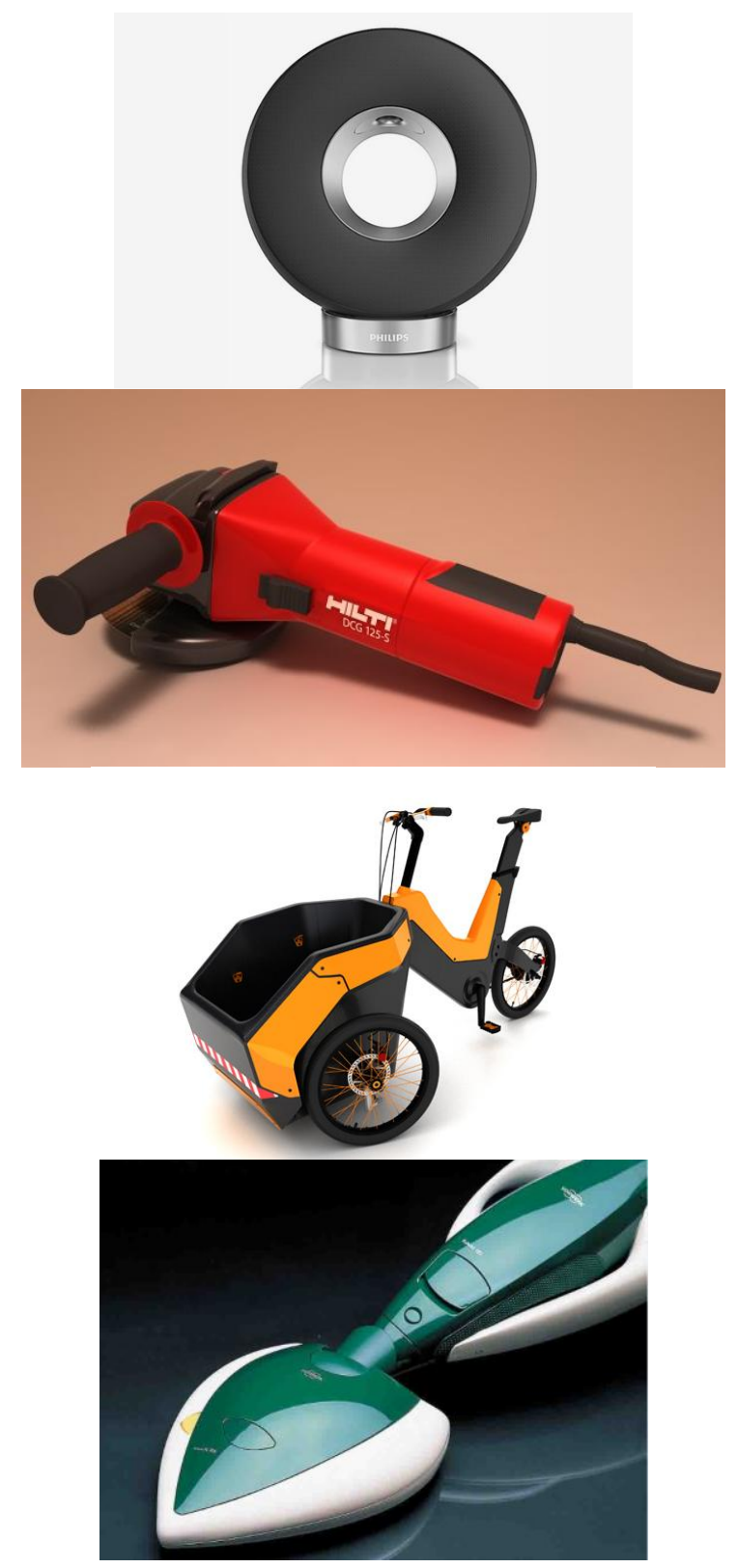

Figure 1. The Examples of the Modern Industrial Product Art Design

In this paper, we conduct research on modern industrial product art design new pattern from the perspective of color design and beautification [3]. Color is the first element of product visual design and good product color design can not only attract the attention of consumers. And in product design art show at the same time, the architect to design the emotions more effectively communicate to consumers through color, enhance consumers' deep impression of product 
and product brand. In the next sub-sections, we will discuss the issues in detail.

\section{Our Proposed Design Pattern and Methodology}

The Basic Principles of Color Design and Beautification. Shape and color of the products is inseparable. Product color if handled well, can coordinate model or make up for the insufficient, make the product more easily won the favor of consumers, receive the twice the result with half the effort. On the other hand, if improper handling of product's color which can destroy the whole beautiful product modeling, even damage the user's mood. Product color is the first standard of color, shape, color to help shape and color brightness. To achieve such effect, it will hold good tonal choice. Hue is the overall color feeling control and unified global role of color design elements. Warm color make the person feel warm, cool color moves makes the person feels cold and cheerless, give priority to with high of warm color tone can make a person excited, gives priority to tone with the cool color with low elements can let a person calm; Tall lightness color gives a person the sense light bright, lively, low lightness color gives a person dark, solemn feeling. Second, the color has the structure function. Structure and function of the color is color affect the ability to detect object, and through different color design can influence the visual perception of the observers. In this case, the color became visible structure can affect the product. Color has the effect of synthetic-aperture and charm and different color can make the person produces different emotional associations. Color collocation is proper, the packaging will be particularly conspicuous, when faced with a wide variety of goods, consumers can impress the moment, must be those who have distinctive color packaging, so the study of packaging color has important significance. Color like form also has the function of similar language can convey information about the products to the people. If handled well, will be incorporated in the product shape, structure, it can make the products to improve the grade, help to improve the function of the product. In terms of the semantic of product design, color is sometimes compared to form the clear.

Material and color influence each other. Material is the carrier of color and the color can't be free materials and exist: the color and texture of a foil material. Products to people are the feeling of the material of material, color, processes the result of joint action. Beautiful color brings beauty to enjoy, different color gives a person the feeling, pure and clean white gives a person is feeling, pink let a person feel lovely and lively, blue, let a person feel happy is static, the purple represents mystery. Each color has a different meaning, however, be match together of the time and the other meaning. So, good color, whether small products or outdoor advertising, both Mercedes cross-country and high-rise buildings, can give a person feel cheerful and pleasing to the eye, at the same time also can let people remember. The same color scheme used in different materials will after different surface treatment will present a different effect. Designing packaging color should choose as far as possible to represent the brand image of color, can use product brand image color or the standard color of the enterprise, to help consumers to the brand identification, help them to choose, to better integration of brand image also has a positive role. So the color of the packaging can't only think about fashion and change, also to pay attention to the appropriate product brand image consistent and lasting.

\section{The Modern Industrial Product Art Design.} Industrial product appearance modelling is the precondition that the present characteristics, only the appearance of the industrial product modelling can reflect the unique charm of products, is likely to attract the attention of the audience, prompting the audience to buy these industrial products. If less attractive appearance style of industrial products, it is easy to cause the 
loss of part of the audience, so as to make the industrial products is gradually being eliminated by the market. Form is the key of the product appearance design, only the design with unique charm of the form of human nature, to better attract the audience's attention, especially in the form of industrial products. In industrial product appearance design, the designer to design the high attractive appearance shape, is the need for serious and detailed market research, according to the function of industrial products and cultural value, clear product appearance design, then according to aesthetic characteristic, adopt scientific and reasonable design method for the exterior form design, in order to ensure that the appearance of the design of industrial product form can have a strong appeal.

Color is one of the main elements of the application of image design, its application in the design are the most common. And with the continuous development of social economy, people's living standards gradually improved, which makes people in the pursuit of material needs at the same time, for their own spiritual needs about more and more attention. The application of color not only can bring audience extremely strong sensory stimulation, can also be very good embodies the connotation of product value. In appearance design of industrial products, the realization of color mainly accomplished through the use of paint and color that play the role of is divided into two kinds, one is with the appearance of the product modelling, enable it to become more dynamic, and thus different from black and white only before modelling product appearance, the other is a protective material of product production. As for the means and methods to the design procedure of system construction, make the art design has a clear purpose, is in numerous design scheme out a best solution, in fact, the best solution in endless scheme may be not. When we take out a best solution at the same time means that we unilaterally lost many excellent designs. But in the long term, the world around us will lack of diversity and become monotonous, there are no more beautiful. Under the principle of simplification, visual identification of the fuzzy and convey obstacles, more because of its lack of pluralistic aesthetic emotion, seriously block the affinity of the enterprise to the public. Modern industrial product design in addition to the level of science and technology, but also the visual art is reflected in the design process. Abroad the industrial product designers explicitly pointed out that a good industrial products, it is in itself a handicraft. The art of product color design including the artistic design and the rationality of design and the artistic quality of product color design is to point to by comparing the harmonic, balanced and stable, ratio and rhythmic movements art processing technique to apply different colors of products, outstanding product aesthetic feeling, shaping products and brand image.

The New Pattern for the Design. Interaction design is based on human psychological needs and behavior demand as a starting point, the function of the product carries on the summary and arrangement, and then integrate the design more simple and practical application. From a user's point of view, interaction design is a kind of can let eliminate strangeness, between people and products in more quickly understand the use function, perceived product design goal which can skilled grasp the product application design. Interaction design product will not provide extra functionality, and try to reduce the error in the use of the opportunity, can be said to be in the gauge people's behavior and psychological activity again after the adding of science and technology, fully respect and basic aesthetic of human body engineering, follow the principle of scientific, rational, users in the process of using feel pleasant and convenient. Technology is the foundation of industrial product design, not as a function of the advanced technology support, products do not achieve the user wishes of skills and nature will not get the favor of consumers. And the industrial technology put forward new 
requirements, also is the important power to promote the development of science and technology. Art beauty element also can't be ignored, in the products of the same kind of functions and artistic appreciation value will no doubt more popular, will also be more competitive in the market promotion. In industrial product market increasingly rich, as well as market competition becomes increasingly fierce today, industrial production and appearance modelling design must be to meet the needs of the audience as the goal, and the appearance of the product not only can fully embody the value of the product, also want to meet the personalized needs of audience, otherwise will be because of the appearance of industrial products not attractive enough, leading to the loss of part of the audience. In appearance design of industrial products, have a direct impact on the appearance of credibility factor is form, only the appearance of the designed high stability, the reliability of industrial products can be improved, the attraction of the product can be improved and industrial products audience also is likely to expand which is meaningful.

\section{Conclusion}

In this paper, we conduct research on modern industrial product art design new pattern from the perspective of color design and beautification. The essence of design research is to realize the success of the product design, in the loop. Color research plays an important role. Through study of product color, culture, and the property of the product color and study the correlation of product characteristics, chooses a kind of both to appropriate reaction product related information. Our method provides the novel paradigm for the art design pattern for the industrial products which will not only enhance the current design methodology but help modify the design ideals.

\section{References}

[1] Ren, L. M. (2014). Study of modern industrial design aesthetic factor based on art design. Journal of Jilin Teachers Institute of Engineering \& Technology.

[2] Song, F. (2014). Analysis on the mode of productbility studio practice of art-design profession. Journal of Mudanjiang College of Education.

[3]Zhao, Y. Y., Chen, L. L., Yu, S. H., \& Chen, J. X. (2014). The revelation research of folk paper-cut creation concept on modern product design. Advanced Materials Research, 933. 